\title{
Effects of Film Morphology and Surface Chemistry on the Direct Electrochemistry of Cytochrome $c$ at Boron-Doped Diamond Electrodes
}

\author{
Yingrui Dai, Denis A. Proshlyakov and Greg M. Swain ${ }^{a^{*}}$ \\ ${ }^{a}$ Department of Chemistry, Michigan State University, East Lansing, MI 48824
}

\begin{abstract}
$\underline{\text { Abstract }}$
\end{abstract}
The effects of film morphology and surface termination on the direct electron transfer of horse heart cytochrome $c$ on boron-doped ultrananocrystalline (B-UNCD) and microcrystalline (B-MCD) diamond thin-film electrodes were investigated. Quasi-reversible, diffusion-controlled cyclic voltammetric responses were observed on oxygen-terminated (atomic O/C $\sim 0.015$ ), but not hydrogen-terminated (atomic $\mathrm{O} / \mathrm{C} \sim 0.02$ ) diamond thin films. The effect of the surface termination was the same for both the nanostructured B-UNCD film with $\mathrm{sp}^{2}$-bonded carbon atoms in the grain boundaries and the well faceted B-MCD film with micron-sized grains and largely devoid of $\mathrm{sp}^{2}$ carbon. Stable cyclic voltammetric $i-E$ curves were recorded with cycling for both oxygenterminated films indicating the absence of protein denaturation and electrode fouling. The peak currents increased linearly with the square root of the scan rate and the protein concentration; both indicative of a reaction rate limited by semiinfinite linear diffusion of the protein. Similar heterogeneous electron-transfer rate constants were observed for oxygen-terminated B-UNCD $\left(3.48( \pm 1.25) \times 10^{-3}\right.$ $\mathrm{cm} / \mathrm{s})$ and B-MCD films $\left(2.38( \pm 0.72) \times 10^{-3} \mathrm{~cm} / \mathrm{s}\right)$. The results clearly reveal that the oxygen-terminated surface is more active for electron-transfer with this soluble redox protein than is the hydrogen-terminated surface. The film 
morphology does not influence the diffusion-controlled response of the redox protein.

* To whom correspondence should be addressed.

Email: swain@chemistry.msu.edu. 


\section{Introduction}

Mammalian cytochrome $c$ is a small $(\sim 12 \mathrm{kDa})$, water-soluble heme protein that functions as an electron carrier between cytochrome $c$ reductase and cytochrome $c$ oxidase; components of oxidative phosphorylation $[1,2]$. The redox partners of this protein are membrane bound, whereas the protein resides in the cytosol. The redox process of this protein involves its heme cofactor shuttling between the ferric $\left(\mathrm{Fe}^{+3}\right)$ and ferrous $\left(\mathrm{Fe}^{+2}\right)$ oxidation states. Cytochrome $\mathrm{c}$ electron transfer is believed to occur at the solvent-exposed edge of the heme group by an outer-sphere mechanism [1-6]. Appropriate "docking" of the cytochrome $c$ with these redox enzymes is critical for rapid electron transfer [3]. For rapid electron transfer, appropriate chemical and electrostatic interactions with an electrode are necessary to properly orient the heme edge of the redox protein close to the surface [3-7]. Electrostatic effects are important for properly orienting the protein with the redox partners in the "docked" state to facilitate electron transfer [1-7].

The redox behavior of cytochrome $c$ at various solid electrodes has been studied extensively over the years [7-17]. One goal for this work has been to learn about the importance of electrostatic effects and electrode interfacial structure (hydrophobic/hydrophilic interactions) on electron transfer with the protein. This protein is a good model system for investigating the fundamental aspects of biological electron transfer both when the protein is dissolved in solution and when it is confined to a chemically-modified electrode surface [8-17]. 
In general for all electrodes, two factors are necessary for rapid cytochrome $c$ electron transfer: (i) a highly purified form of the protein dissolved in solution and (ii) electrode pretreatment and or chemical modification to produce a clean, hydrophilic/oxophilic and or negatively charged surface [18,19]. For carbon electrodes, Armstrong and coworkers reported that the electron-transfer rate for cytochrome $c$ on the edge plane of pyrolytic graphite is much faster than on the basal plane sites due to the higher oxygen/carbon $(\mathrm{O} / \mathrm{C})$ ratio of edge plane $[10,17]$. Chemical interactions are possible with the "oxygenated" edge plane sites more so than with the oxygen-poor basal plane sites. The key functional groups are carboxylates that are deprotonated at physiological $\mathrm{pH}$. Electrostatic interactions between the positively charged heme edge and the negatively charged electrode surface lead to proper orientation and positioning of the protein such that the activation barrier for electron-transfer is lowered. The redox protein's orientation and distance from the electrode are critical factors.

In recent years, boron-doped diamond has emerged as a useful new carbon electrode for electroanalytical measurements because of some unique properties [20-24]. Boron-doped diamond electrodes can be single crystal or polycrystalline. Polycrystalline diamond films can be subdivided into three types: microcrystalline, nanocrystalline or ultrananocrystalline [25]. Microcrystalline diamond thin-films are grown in a hydrogen-rich chemical vapor deposition (CVD) environment and are composed of well-faceted crystallites that are micrometers in dimension [26]. Nanocrystalline diamond thin films are also deposited in a 
hydrogen-rich CVD environment. Preparing the substrate surface to produce a high initial nucleation density is necessary to form nanocrystalline diamond. Such substrate preparation leads to a continuous film in a short deposition time with grains or crystallites having dimensions of tens of nanometers [23]. Finally, ultrananocrystalline diamond thin films are grown in an Ar-rich CVD environment, being pioneered by Gruen and coworkers at Argonne National Laboratory [27]. These films consist of 50-100 nm aggregates of diamond grains ( 15 nm diam.) and are grown under conditions where a high rate of renucleation exists. Unlike nanocrystalline diamond, ultrananocrystalline diamond films have high-energy, high-angle grain boundaries that contain $\pi$-bonded carbon $[27,28]$. There have been a few reports of direct electron transfer with redox proteins, namely cytochrome $c$, at unmodified and chemically-modified diamond (polycrystalline) electrodes [29-38]. Diamond's unique microstructure and resistance to electrode fouling have been drivers of this work.

Our original work with dissolved horse heart cytochrome $c$ utilized a boron-doped microcrystalline diamond thin-film electrode that was supposed to be low in surface oxygen due to growth in a hydrogen-rich plasma [29]. Regardless of the electrode, chromatographically-purified protein is absolutely necessary to realize relatively large heterogeneous electron-transfer rate constants, $\mathrm{k}_{\text {app }}^{\mathrm{r}} \sim 1 \times 10^{-3} \mathrm{~cm} / \mathrm{s}[18,19,29,38]$. At about the same time, Marken and coworkers [30] reported on studies of dissolved cytochrome $c$. In their paper, a boron-doped diamond microcrystalline diamond thin-film electrode, polished 
with alumina and oxidatively pretreated, was used. Reversible electron transfer for horse heart cytochrome $c$ was observed. In contrast, little redox activity was observed on the oxidatively pretreated-only electrode. Evidence was provided that the electron transfer occurred with the protein in a surface confined state. Clearly, the alumina played a role in facilitating the electron transfer and one can surmise that residual grit on the electrode surface possibly functioned as an adsorption site for the protein.

Since the publication of these initial two papers, several others have been emerged in the literature, all showing that the most reversible electrochemistry for cytochrome $c$ is observed at diamond electrodes functionalized with carbonoxygen groups or molecular linkers that are oxygenated and or charged [31-38]. Reversible electrochemistry on these modified surfaces has been reported for both dissolved and immobilized protein. One paper by the Nebel group, for example, showed protein denaturation on a hydrogen-terminated diamond electrode with no observed electrochemical activity [32].

Given the conflicting findings between our original work on low-oxygen, hydrophobic, hydrogen-terminated diamond and the literature reports for oxygenated or chemically-modified diamond, we decided to revisit this research. Support for our original finding of quasi-reversible electron transfer on a hydrophobic, low-oxygen diamond film was the reported importance of hydrophobic interactions for properly orienting the heme group of cytochrome $c$ by Rivas et al. [39]. The authors reported rapid electron transfer $\left(\mathrm{k}^{0} \sim 10^{-3} \mathrm{~cm} / \mathrm{s}\right)$ 
for cytochrome $c$ immobilized on a Ag electrode modified with a hydrophobic selfassembled monolayer (SAM), n-alkanethiol HS- $\left(\mathrm{CH}_{2}\right)_{\mathrm{n}}-\mathrm{CH}_{3}$ [39]. Their work showed that hydrophobic interactions with the electrode are also important for properly orienting the protein to promote electron transfer. Compared with electrostatically-bound cytochrome $c$, the hydrophobic interactions lead to the same structural changes of the heme and relatively large rate constants [39].

We report herein on a systematic investigation of the electron-transfer kinetics for horse heart cytochrome $c$ at boron-doped diamond electrodes as a function of the (i) film morphology (ultrananocrystalline (B-UNCD) and microcrystalline (B-MCD) thin films), and (ii) surface chemistry (oxygen- and hydrogen-termination). Cyclic voltammetry was used to study the redox activity of dissolved protein as a function of scan rate and $\mathrm{pH}$, and XPS was used to quantify the surface chemistry of the electrodes.

\section{Experimental}

2.1. Diamond Thin-Film Deposition. The boron-doped microcrystalline (B-MCD) and ultrananocrystalline (B-UNCD) diamond thin films were deposited on highly conductive $p$-type Si (100) substrates $\left(\sim 10^{-3} \Omega-\mathrm{cm}, 0.05 \mathrm{~cm}\right.$ thick $\times 1 \mathrm{~cm}^{2}$ area, Virginia Semiconductor Inc., Fredricksburg, VA) using a commercial microwaveassisted chemical vapor deposition (CVD) system (1.5 kW, formerly ASTeX Inc., now Seki Diamond (JAPAN)). The substrates were pretreated by mechanically scratching with dry $0.1 \mu \mathrm{m}$ diameter diamond powder (GE Superabrasives, 
Worthington, $\mathrm{OH}$ ) for $5 \mathrm{~min}$ on a felt polishing pad. The scratched substrates were then ultrasonically cleaned in ultrapure water, isopropyl alcohol (IPA), acetone, IPA, and finally, ultrapure water for $10 \mathrm{~min}$ each to remove polishing debris from the surface. The clean scratches and residual powder particles serve as the initial nucleation sites for diamond growth.

The B-MCD films were deposited using $1.0 \mathrm{sccm}$ (standard cubic centimeters per minute) of $\mathrm{CH}_{4}$ and $197.5 \mathrm{sccm}$ of $\mathrm{H}_{2}(0.5 \% \mathrm{v} / \mathrm{v})$ as the source gas mixture, $1 \mathrm{~kW}$ of microwave power, a system pressure of 45 Torr, a substrate temperature of $\sim 750 \stackrel{\circ}{\circ}$ (estimated via a single filament optical pyrometer) and a growth time of 7-10 h. The B-UNCD films were deposited using gas flow rates of $1.0,92.5$ and $5 \mathrm{sccm}$ for $\mathrm{CH}_{4}, \mathrm{Ar}, \mathrm{H}_{2}$, respectively. Deposition was carried out using $800 \mathrm{~W}$ of plasma power under system pressure of 140 Torr and a substrate temperature of $\sim 750{ }^{\circ} \mathrm{C}$ for $2 \mathrm{~h}$. All gases were ultrahigh purity ( $\geq 99.999 \%)$ grade $\left(\mathrm{CH}_{4}\right.$ and $\mathrm{H}_{2}$ from AGA Specialty Gas, Cleveland, $\mathrm{OH}$; Ar from BOC Group, Inc., Murray Hill, NJ). Both the B-MCD and B-UNCD films were doped during deposition by adding $10 \mathrm{ppm} \mathrm{B}_{2} \mathrm{H}_{6}$ in $\mathrm{H}_{2}$ at $1.5 \mathrm{sccm}$ to the source gas mixture $\left(0.1 \% \mathrm{~B}_{2} \mathrm{H}_{6}\right.$ diluted in $\mathrm{H}_{2}$, Matheson Gas Products, Inc.). Total source gas flow rates for the B-MCD and B-UNCD films were 200 and $100 \mathrm{sccm}$, respectively. Following the deposition period, the $\mathrm{CH}_{4}$ and $\mathrm{B}_{2} \mathrm{H}_{6}$ gas flows were stopped and the films remained exposed to the $\mathrm{H}_{2}$ (MCD) or $\mathrm{Ar} / \mathrm{H}_{2}$ (UNCD) plasma for an additional 5-10 min. The plasma power and pressure were then slowly reduced over a $15-30$ min period to cool the samples to a temperature 
around $400{ }^{\circ} \mathrm{C}$ with the plasma ignited (i.e., in the presence of atomic hydrogen). Post growth annealing in atomic hydrogen is essential for removing adventitious nondiamond carbon impurity via gasification, minimizing dangling bonds, and ensuring full hydrogen termination. Importantly, this annealing procedure is different from that used in our prior work [29], a point that will be discussed further below. The plasma power was then turned off and the films were cooled to room temperature under a flow of $\mathrm{H}_{2}(\mathrm{MCD})$ or $\mathrm{Ar} / \mathrm{H}_{2}$ (UNCD). Both film types had a nominal boron dopant concentration between $5 \times 10^{20}$ and $5 \times 10^{21} \mathrm{~B} \mathrm{~cm}^{-3}$ and a film resistivity of $\sim 0.01 \Omega$-cm, or less. The dopant concentration was determined by boron nuclear reaction analysis (Surface Characterization Facility, Case Western Reserve University).

2.2. Surface Termination. After growth, the diamond films were chemically treated to remove adventitious metal and $\mathrm{sp}^{2}$-bonded nondiamond carbon impurities from the surface by (i) exposure to $3: 1 \mathrm{HCl}^{-} \mathrm{HNO}_{3}(\mathrm{v} / \mathrm{v})$ for $30 \mathrm{~min}$ at $\sim 50{ }^{\circ} \mathrm{C}$ followed by a rinse with ultrapure water and then (ii) exposure to $30 \%$ hydrogen peroxide (Fisher Scientific) for $30 \mathrm{~min} \sim 50{ }^{\circ} \mathrm{C}$ followed by a rinse with ultrapure water. This chemical oxidation introduces surface carbon-oxygen functionalities, which we refer to as "oxygen-terminated" in the text. This treatment increases the $\mathrm{O} / \mathrm{C}$ atomic ratio from $\sim 0.02$ to $0.14-0.23$, as determined from X-ray photoelectron spectroscopy (XPS) measurements. To regenerate the low oxygen, hydrogen-terminated surface, the diamond films were placed back into a dedicated CVD reactor for a 30-min hydrogen-plasma treatment under a 
microwave power of $1000 \mathrm{~W}$, a system pressure of 35 torr, and $\mathrm{H}_{2}$ gas flow of $200 \mathrm{sccm}$. The films were slowly cooled in the atomic hydrogen plasma over a 15-30 min period, as described above. We refer to these films as "hydrogenterminated" in the text. The atomic O/C ratio of this surface is $\leq 0.02$.

2.3. Cyclic Voltammetry. All electrochemical measurements were performed at room temperature in a single compartment glass cell using a computer-controlled potentiostat (CH Instruments, Inc., Austin, TX) [20]. A standard three-electrode configuration was employed. The electrochemical cell was housed inside a grounded Faraday cage for electrical shielding. The working electrode was clamped against a clean Viton o-ring at the bottom of the cell. Backside electrical contact was made to the diamond working electrode by scratching the conducting Si substrate with abrasive paper and then cleaning and coating the area with graphite from a standard pencil or a dab of $\mathrm{Ag}$ paste. This procedure produces good ohmic contact between the electrode and a copper currentcollector plate. The geometric area of the electrode exposed to the solution was $0.2 \mathrm{~cm}^{2}$. A silver/silver chloride reference electrode (saturated $\mathrm{KCl}, E^{\circ}=-45 \mathrm{mV}$ vs. SCE) was used, which was placed inside a cracked-glass capillary filled with $1 \mathrm{~mol} \mathrm{dm}^{-3} \mathrm{KCl}$ and positioned in close proximity to the working electrode. A large area carbon rod served as the counter electrode and was positioned normal to the working electrode. Solutions were typically deaerated with $\mathrm{N}_{2}$ gas bubbling for at least 20 min prior to any voltammetric measurement. Solutions remained blanketed with the gas during a measurement. 
2.4. X-ray Photoelectron Spectroscopy (XPS). XPS was used to determine the oxygen and carbon atomic ratios $(\mathrm{O} / \mathrm{C})$ on the diamond film surfaces [40-45]. XPS spectra were obtained using a PHI 5400 XPS spectrometer (Physical Electronics, Inc.) with an Mg X-ray source. A take-off angle of 45 degrees was used for all measurements at a base pressure of ca. $5 \times 10^{-9}$ Torr. The atomic percentage of each element was determined from peak areas divided by appropriate bulk sensitivity factors specific for the PHI 5400 instrument and the supplied deconvolution software.

2.5. Chemicals. All solutions were prepared with ultrapure water from a Barnstead E-pure water purification system (Fisher Scientific, Inc.) with a resistivity of $\sim 18 \mathrm{M} \Omega \times \mathrm{cm}$. Stock solutions of cytochrome $c$ (in $0.3 \mathrm{~mol} \mathrm{dm}^{-3} \mathrm{NaCl}$, $10 \mathrm{mmol} \mathrm{dm}{ }^{-3}$ Tris- $\mathrm{HCl}$ buffer, $\mathrm{pH}$ 7) were prepared by chromatographically purifying and concentrating horse heart cytochrome $c$ (Sigma-Aldrich Corp.) using a published procedure [46-48]. Cytochrome c concentrations were determined spectrophotometrically at $550 \mathrm{~nm}$ from the difference in the absorbance of the ferrous and ferric forms of the protein using $\Delta \varepsilon_{550 \mathrm{~nm}}=21 \mathrm{~cm}^{-1}$ $\mathrm{mM}^{-1}[49,50]$. Ferricytochrome $c$ was reduced by a small amount of sodium dithionite. Cytochrome $c$ in potassium phosphate buffers was prepared by repeated dilutions by buffers of desired $\mathrm{pH}$ and concentration followed by centrifugations using an Amicon ${ }^{\circledR}$ Ultra-15 centrifugal filter (Millipore). 
3.1. XPS Measurements. In our prior report, data on the oxygen content of the diamond film surface were not reported [29]. It was presumed that the surface was low in oxygen given the relatively high contact angle for water and the fact that the film was grown in a hydrogen-rich plasma, which favors a low oxygen, hydrogen surface termination [29]. Presently, we used XPS to characterize the elemental composition in the near-surface region of B-MCD and B-UNCD films "as deposited", after oxygenation, and after rehydrogenation. Typical XPS spectra for "as deposited", oxygen-terminated and hydrogen-terminated B-UNCD surfaces are presented in Figure 1. The spectrum for the as-deposited film showed a sharp C 1s peak near $284.5 \mathrm{eV}$ and a small, but quantifiable, $\mathrm{O} 1 \mathrm{~s}$ peak at ca. $532 \mathrm{eV}$ with an $\mathrm{O} / \mathrm{C}$ atomic ratio of 0.05 . The plasmon loss feature at $318.5 \mathrm{eV}$ results from energy losses of the outgoing photoelectrons upon excitation of the bulk and surface plasmons of diamond [51]. Its presence indicates high purity of the diamond film [51]. After chemical oxidation, the $O 1 \mathrm{~s}$ peak intensity increased considerably to an $\mathrm{O} / \mathrm{C}$ value of 0.17 . This is typically the maximum ratio obtainable on diamond films and is similar to the value of 0.18 reported for a diamond electrode treated in an oxygen plasma or exposed to acidic environments [40-45]. The rehydrogenation step converted the diamond 
surface back to a hydrogen-termination by removing surface oxygen and reducing the $\mathrm{O} / \mathrm{C}$ ratio to 0.02 . Identical spectra were obtained for "as deposited", oxygen-terminated, and hydrogen-terminated B-MCD films (data not shown).
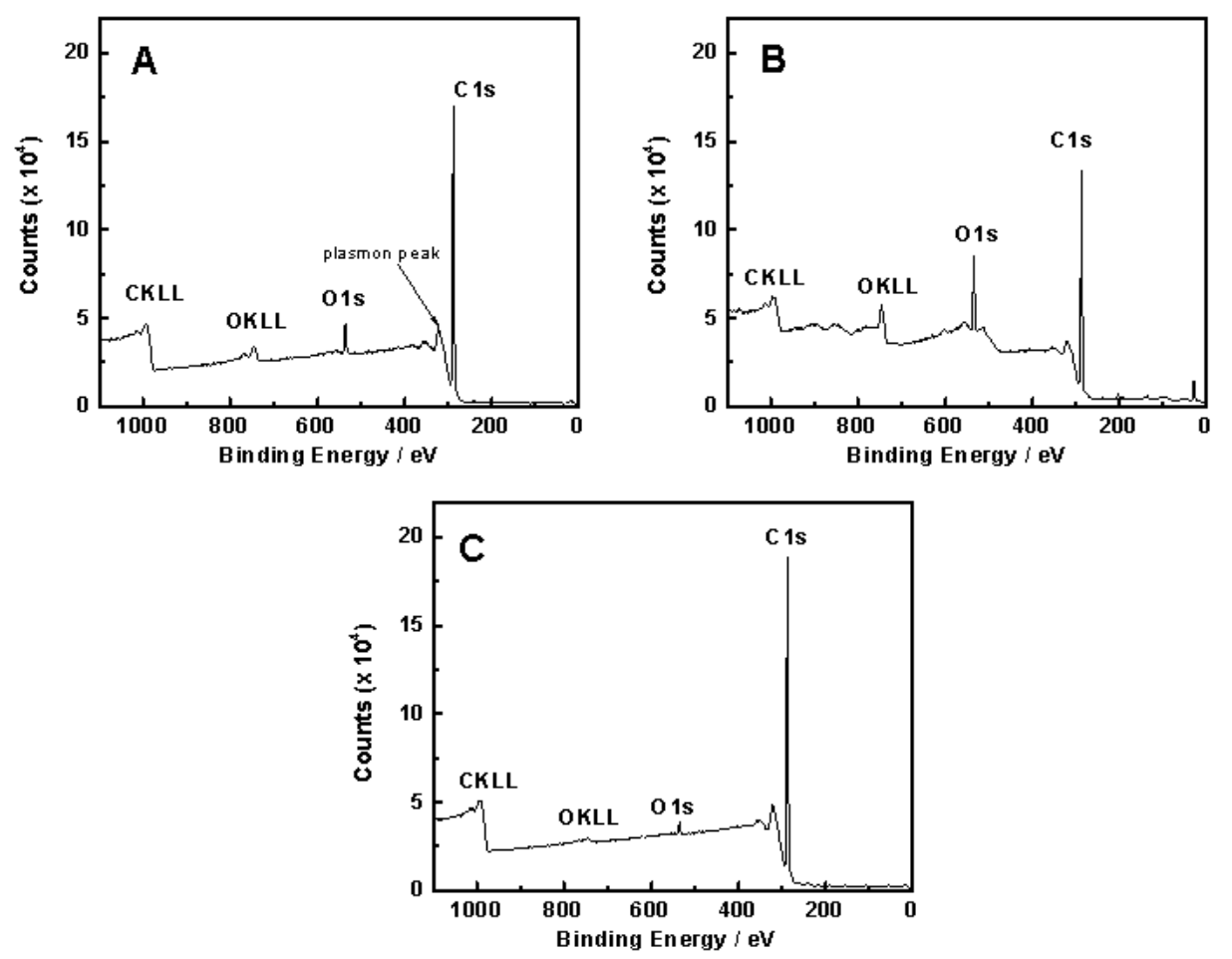

Figure 1. X-ray photoelectron survey spectra of B-UNCD electrodes (A) as-deposited, (B) after oxygenation (oxygen terminated) and (C) after rehydrogen (hydrogen terminated). 

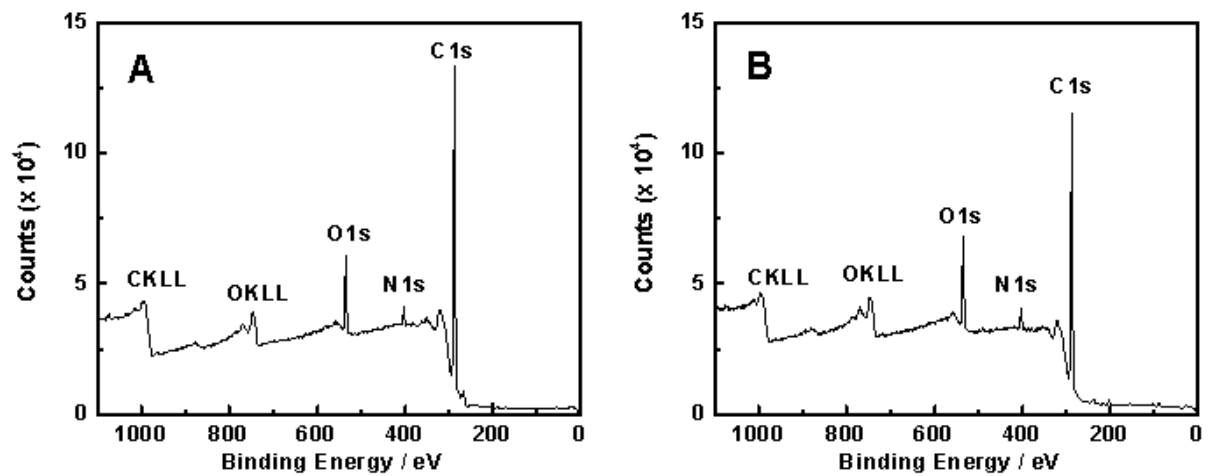

Figure 2. X-ray photoelectron survey spectra of oxygen-terminated $(A) B-M C D$ and (B) B-UNCD electrodes after immersion and potential cycling in a solution of $0.1 \mathrm{mmol}$ $\mathrm{dm}^{-3}$ cytochrome $c$ in $0.1 \mathrm{~mol} \mathrm{dm}^{-3} \mathrm{NaCl}+0.01 \mathrm{~mol} \mathrm{dm}^{-3}$ Tris-HCl buffer ( $\mathrm{pH}$ 7). The electrodes were rinsed with ultrapure water after the cycling.

Measurements were performed to probe for residual protein adsorption on both diamond electrodes. The electrodes were subjected to multiple cyclic voltammetric scans in a $0.1 \mathrm{mM}$ cytochrome $c$ solution over the heme $\mathrm{Fe}(\mathrm{II} / \mathrm{III})$ redox transition between 0.3 and -0.2 V. XPS survey spectra shown in Figure 2 for oxygen-terminated B-UNCD and B-MCD electrodes cycled and rinsed reveal the presence of a weak surface nitrogen signal $(\mathrm{N} \mathrm{1s}, \mathrm{ca} .400 \mathrm{eV})$ in addition to the $\mathrm{C} 1 \mathrm{~s}$ and $\mathrm{O} 1 \mathrm{~s}$ signals. The increased $\mathrm{N}$, an element normally not detected on the diamond film surface, is consistent with some residual protein on the surface. Interesting, however, is that fact that no signals for Fe $\left(2 p_{3 / 2}, c a .710 \mathrm{eV}\right)$ or $\mathrm{S}(2 \mathrm{p}$, ca. $165 \mathrm{eV}$ ) were detected. It is unclear why no Fe or $\mathrm{S}$ was detected. It is possible that regions of the adsorbed protein containing these elements were buried in adsorbed protein on the surface deeper than the escape depth for the 
photoelectrons. Most importantly, this small amount of residual and presumably denatured protein did not adversely affect electron transfer with dissolved

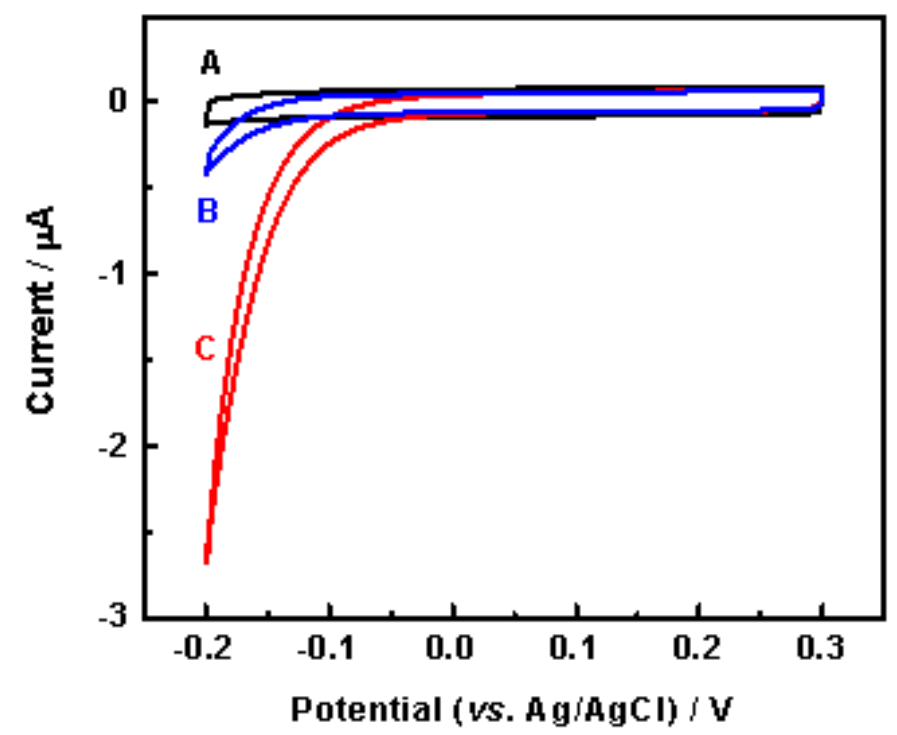

Figure 3. Cyclic voltammetric $i-E$ curves for a hydrogen-terminated B-UNCD film showing (A) the initial background response in $0.1 \mathrm{~mol} \mathrm{dm}^{-3} \mathrm{NaCl}$ and $0.01 \mathrm{~mol} \mathrm{dm}^{-3}$ Tris- $\mathrm{HCl}$ buffer $(\mathrm{pH} 7)$, (B) a repeat background scan after exposure to a cytochrome $c$ solution and (C) the response in $0.1 \mathrm{mmol} \mathrm{dm}^{-3}$ cytochrome $c$ plus $0.1 \mathrm{~mol} \mathrm{dm}^{-3} \mathrm{NaCl}$ and $0.01 \mathrm{~mol} \mathrm{dm}^{-3}$ Tris-HCl buffer $(\mathrm{pH}$ 7). Scan rate $=20 \mathrm{mV} \mathrm{s}^{-1}$. Electrode area $=0.2 \mathrm{~cm}^{2}$. The scan was initiated at $0.3 \mathrm{~V}$ and the potential swept initially in the negative direction.

cytochrome $c$ molecules. The absence of electrode fouling is clearly evident in the voltammetric data presented below.

\subsection{Cyclic Voltammetric Studies. Figure 3A-C shows a series of cyclic} voltammetric curves for a hydrogen-terminated B-UNCD thin-film electrode. Background curves in $0.1 \mathrm{~mol} \mathrm{dm}^{-3} \mathrm{NaCl}$ and $0.01 \mathrm{~mol} \mathrm{dm}^{-3}$ Tris-HCl buffer ( $\mathrm{pH}$ 7) before $(A)$ and after $(B)$ potential cycling in a cytochrome $c$ solution are presented

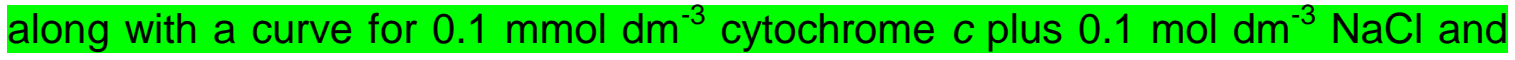
$0.01 \mathrm{~mol} \mathrm{dm}^{-3}$ Tris-HCl buffer ( $\mathrm{pH} 7$ ) (C). XPS confirmed the low oxygen content on this electrode $(\mathrm{O} / \mathrm{C} \leq 0.02)$. In contrast to our previously reported results [29], 

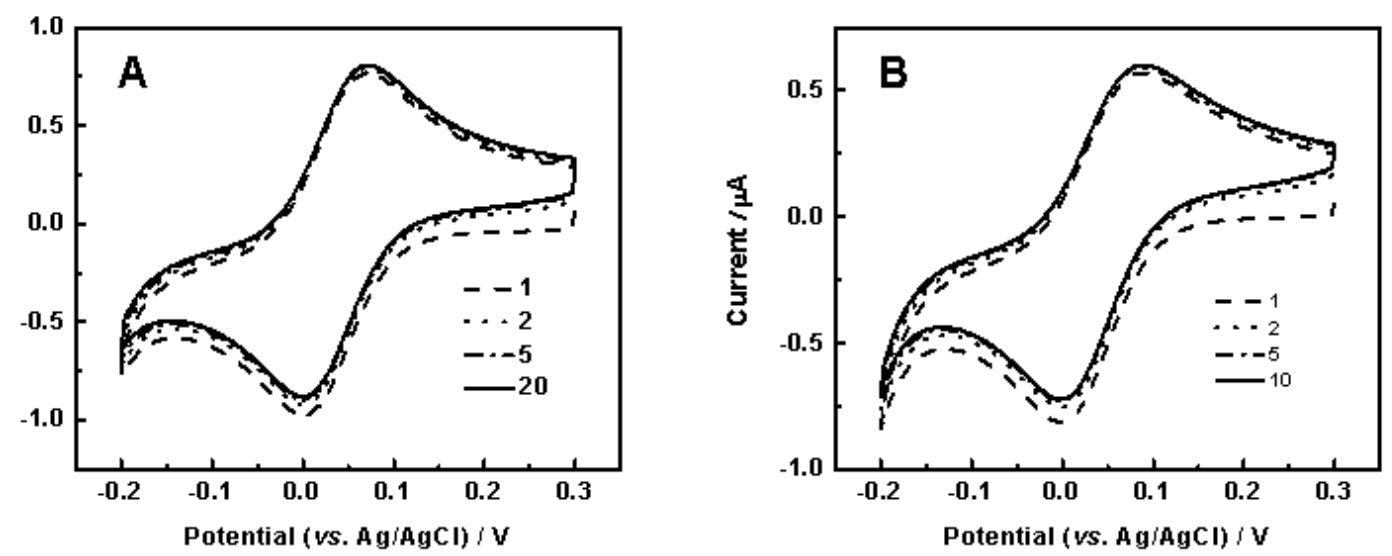

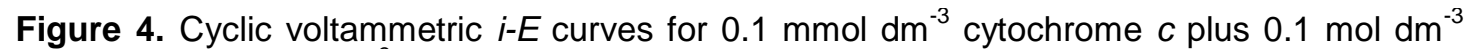
$\mathrm{NaCl}$ and $0.01 \mathrm{~mol} \mathrm{dm}^{-3}$ Tris- $\mathrm{HCl}$ buffer $(\mathrm{pH} \mathrm{7)}$ at oxygen-terminated $(A) B-U N C D$ and $(B) B-$ MCD electrodes. Curves are shown for different scan numbers (1-10). The scans were initiated at $0.3 \mathrm{~V}$ and the potential swept initially in the negative direction.

terminated B-MCD electrodes. This inactivity on the hydrogen-terminated surface is consistent with the results reported by the Nebel group [33]. There is an increase in the cathodic current at $-0.2 \mathrm{~V}$ that develops after a couple of cycles. This current is attributed to the electrochemically irreversible reduction of ferricytochrome $c$ (III) to ferrocytochrome $c$ (II). The fact that the background curves before and after exposure to the protein solution show no current at this potential is confirmation that the current is associated with the protein. This lack of reversibility may be due to protein denaturation as has been previously reported for hydrogen-terminated diamond [33].

A completely different response was observed for oxygen-terminated BUNCD and B-MCD electrodes. Figure 4 shows cyclic voltammograms for both 
electrodes during repeated cycles in a $0.1 \mathrm{mmol} \mathrm{dm}^{-3}$ cytochrome $c$ solution. The oxygen termination was confirmed by XPS $(\mathrm{O} / \mathrm{C}=0.15-0.23)$. Well-resolved oxidation and reduction peaks (heme $\mathrm{Fe}(\mathrm{II} / \mathrm{III})$ ) are seen for both electrodes with no decrease in peak current or change in $\Delta \mathrm{E}_{\mathrm{p}}$ over 10 consecutive cycles. This indicates that there is no significant protein denaturation or electrode fouling during short term cycling at the oxygen-terminated electrode. This result also indicates the residual adsorbed protein, evidenced by the weak N1s signal in the XPS survey scan (Fig. 2), does not inhibit the electron-transfer kinetics. Consistency of voltammetric traces over multiple cycles is indicative of a stable interfacial structure at the electrode surface.

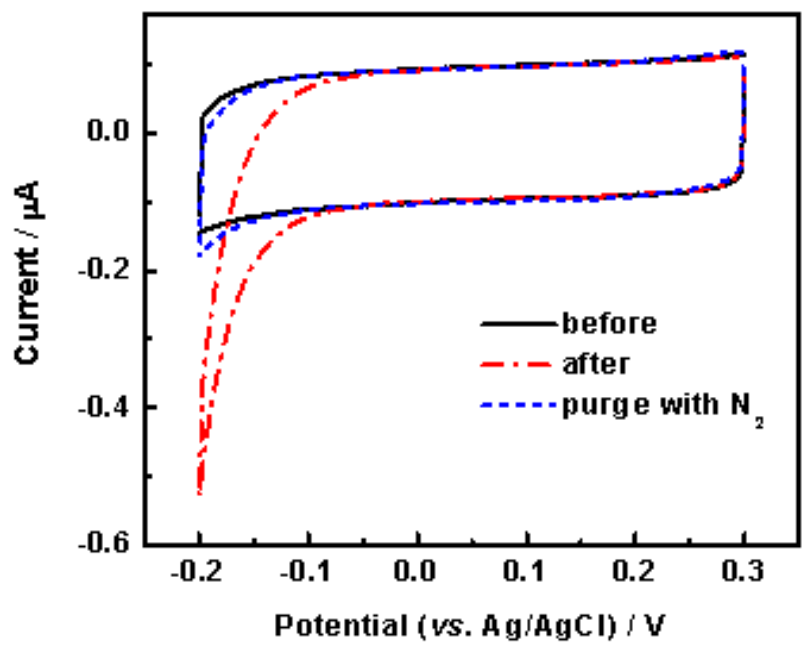

Figure 5. Cyclic voltammetric background $i-E$ curves for an oxygen-terminated B-UNCD electrode in $0.1 \mathrm{~mol} \mathrm{dm}^{-3} \mathrm{NaCl}$ plus $0.01 \mathrm{~mol} \mathrm{dm}^{-3}$ Tris-HCl buffer $(\mathrm{pH} \mathrm{7})$. Scan rate $=20 \mathrm{mV} \mathrm{s}$ 1. Electrode area $=0.2 \mathrm{~cm}^{2}$. The curves were recorded in buffer before (black, solid line) and after (red, dashed dot line and blue, dashed line) cycling in a cytochrome $c$ solution. The black and blue curves were recorded in solutions deaerated with $\mathrm{N}_{2}$ while the red curve was recorded in naturally aerated electrolyte solution. The scan was initiated at $0.3 \mathrm{~V}$ and the potential swept initially in the negative direction. 
Figure 5 shows background cyclic voltammograms of an oxygenterminated B-UNCD electrode before and after potential cycling in a cytochrome $c$ solution. The absence of current peaks in the 0.2 to $-0.1 \mathrm{~V}$ region indicates there is no detectable adsorption of electroactive protein following the redox cycling and subsequent washing of the electrode. There is, however, an increase in the background cathodic current at $-0.2 \mathrm{~V}$ seen for the cytochrome $c$-cycled electrode in the naturally-aerated electrolyte (red curve). This current is reduced after deaerating the solution with $\mathrm{N}_{2}$. In this electrolyte, there would normally be little current for dissolved oxygen reduction at this potential. This result suggests the oxygen reduction reaction may be catalyzed by low levels of residual protein on the surface (see Fig. 2), possibly a denatured protein residue with 5coordinated, catalytic Fe-porphyrin [52,53].

Figure 6 shows cyclic voltammetric $i-E$ curves for cytochrome $c$ on an oxygen-terminated B-UNCD electrode at different scan rates from 2-100 $\mathrm{mV} \mathrm{s}^{-1}$. The midpoint potential $\left(E_{1 / 2}\right)$, measured as the average between the reduction and oxidation peak potentials, remained unchanged at $0.032 \mathrm{~V} v \mathrm{vs} . \mathrm{Ag} / \mathrm{AgCl}$ $(0.229 \mathrm{~V} v s$. $\mathrm{NHE})$ over the probed scan rates. The peak currents and $\Delta \mathrm{E}_{\mathrm{p}}$, as can be seen, both increased with increasing scan rate. Figure $7 A$ and $B$ show plots of the cathodic peak current, $i_{p c}$, and the scan rate ${ }^{1 / 2}, v^{1 / 2}$, and the protein concentration, respectively. The Randles-Sevcik equation predicts a linear relationship between both the peak current, $i_{p}$, and $v^{1 / 2}$ and the analyte 


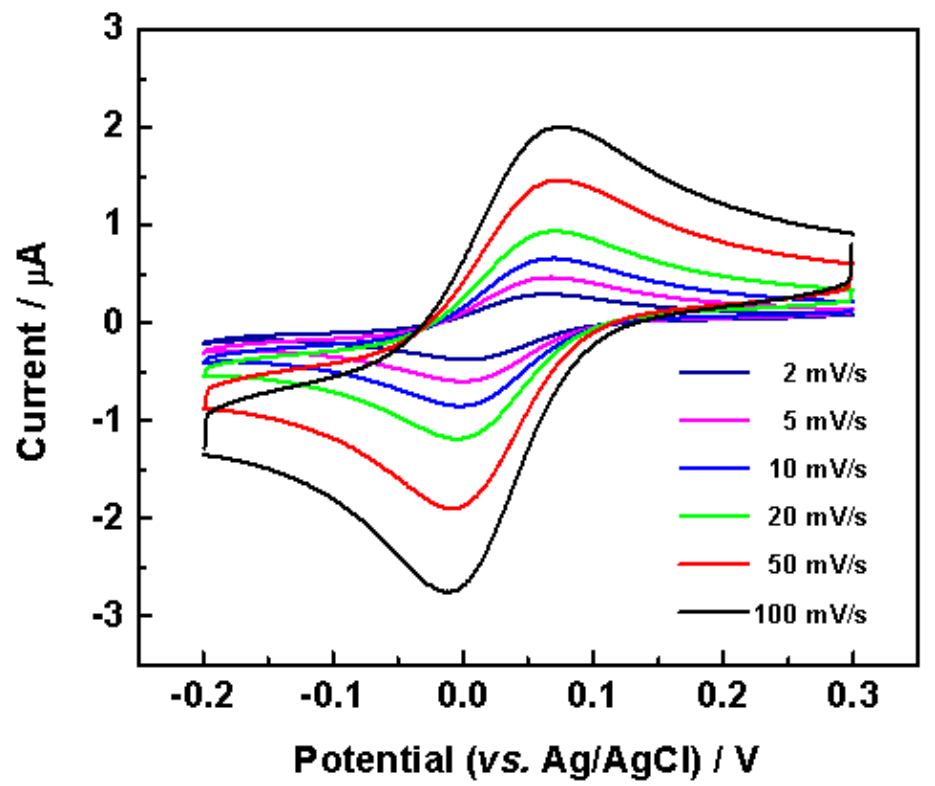

Figure 6. Cyclic voltammetric $i-E$ curves for $0.1 \mathrm{mmol} \mathrm{dm}^{-3}$ cytochrome $c$ in $0.1 \mathrm{~mol} \mathrm{dm}^{-3}$ $\mathrm{NaCl}$ and $0.01 \mathrm{~mol} \mathrm{dm}^{-3}$ Tris- $\mathrm{HCl}(\mathrm{pH} 7)$ on an oxygen-terminated B-UNCD electrode at different scan rates from $2-100 \mathrm{mV} \mathrm{s}^{-1}$. Electrode area $=0.2 \mathrm{~cm}^{2}$. The scan was initiated at $0.3 \mathrm{~V}$ and the potential swept initially in the negative direction. The fifth cycle is shown for each scan rate.

concentration, $\mathrm{C}^{*}\left(\mathrm{~mol} \mathrm{~cm}^{-3}\right)$, for a diffusion-controlled redox reaction according to:

$$
\mathrm{i}_{p}=\left(2.69 \times 10^{5}\right) \mathrm{n}^{3 / 2} A D^{1 / 2} C^{*} v^{1 / 2}
$$

The other variables are as follows: $\mathrm{n}$ (number of electrons transferred per mole), A (electrode area, $\mathrm{cm}^{2}$ ) and $D$ (diffusion coefficient, $\mathrm{cm}^{2} \mathrm{~s}^{-1}$ ). The plots reveal a linear increase in $\mathrm{i}_{\mathrm{pc}}$ with both $v^{1 / 2}$ and $\mathrm{C}$. Similar trends were observed for the oxygen-terminated B-MCD electrodes (data not shown). The diffusion coefficient, $D_{o x}$, was determined from the slope of the $\mathrm{i}_{\mathrm{pc}} v s . v^{1 / 2}$ curve to be $2.63 \times 10^{-6} \mathrm{~cm}^{2}$ $\mathrm{s}^{-1}$ for B-UNCD and $2.09 \times 10^{-6} \mathrm{~cm}^{2} \mathrm{~s}^{-1}$ for B-MCD. 

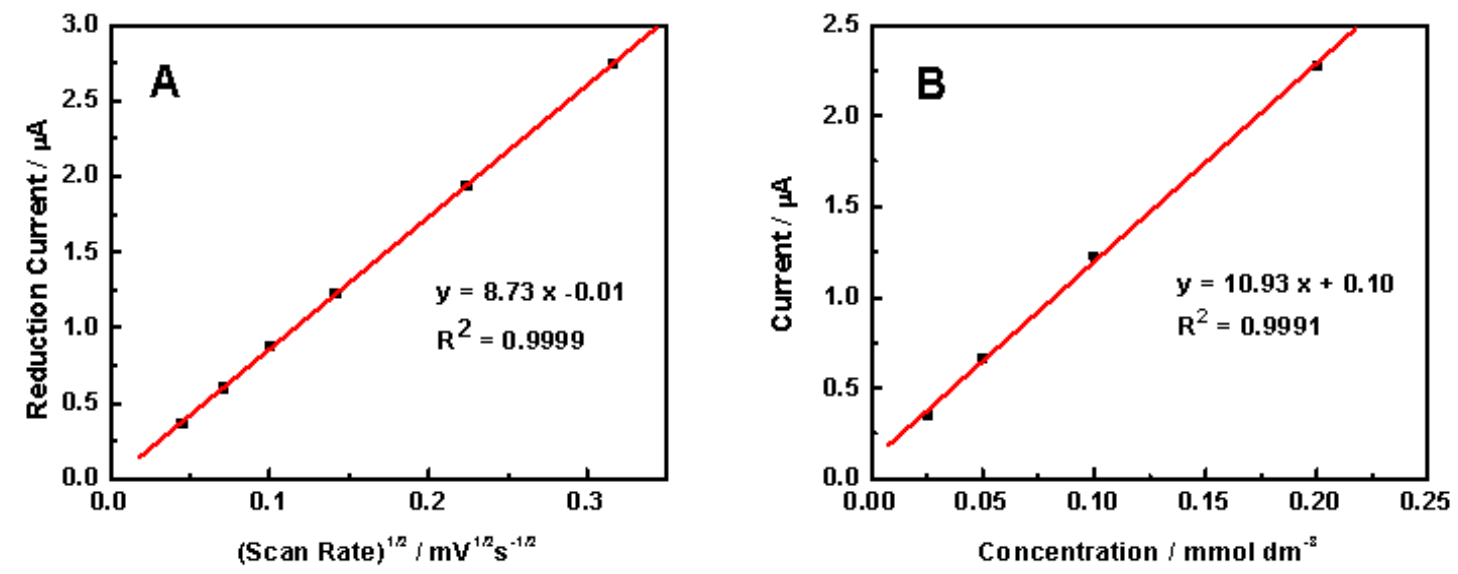

Figure 7. (A) Plot of the reduction peak current, $i_{p c}$, for $0.1 \mathrm{mmol} \mathrm{dm}^{-3}$ cytochrome $c$ in $0.1 \mathrm{~mol}$ $\mathrm{dm}^{-3} \mathrm{NaCl}$ and $0.01 \mathrm{~mol} \mathrm{dm}^{-3}$ Tris-HCl buffer $(\mathrm{pH} 7)$ as a function of the (scan rate) ${ }^{1 / 2}$. (B) Plot of $\mathrm{i}_{\mathrm{pc}}$ versus the cytochrome $c$ concentration in $0.1 \mathrm{~mol} \mathrm{dm}^{-3} \mathrm{NaCl}$ and $0.01 \mathrm{~mol} \mathrm{dm}^{-3}$ Tris- $\mathrm{HCl}$ buffer $(\mathrm{pH} 7)$. Both sets of data were created from cyclic voltammetric i-E curves recorded with an oxygen-terminated B-UNCD electrode. The $i_{p c}$-concentration data are for a $20 \mathrm{mV} \mathrm{s}^{-1}$ scan rate.

The apparent heterogeneous electron-transfer rate constant, $k_{a p p}^{o}$, was calculated from the scan rate dependence of $\Delta \mathrm{E}_{\mathrm{p}}$ using Nicholson's theoretical treatment and assuming a charge-transfer coefficient $\alpha=0.5$ [54]. The nominal values of $k_{\text {app }}^{o}$ were $3.48( \pm 1.25) \times 10^{-3} \mathrm{~cm} \mathrm{~s}^{-1}$ for B-UNCD and $2.38( \pm 0.72)$ $\times 10^{-3} \mathrm{~cm} \mathrm{~s}^{-1}$ for B-MCD. The values are in good agreement, by order of magnitude, with the rate constant we reported in our original work $(1.0( \pm 0.1)$ $\left.\times 10^{-3} \mathrm{~cm} \mathrm{~s}^{-1}\right)$ [29], and other rate constants reported in the literature $[55,56]$. The fact that the calculated $k_{a p p}^{o}$ values are statistically indistinguishable for the different scan rates examined here, as shown in Table 1, indicates that uncompensated ohmic resistance within the electrode and the electrolyte solution are not significantly influencing the voltammetric curve shapes. 

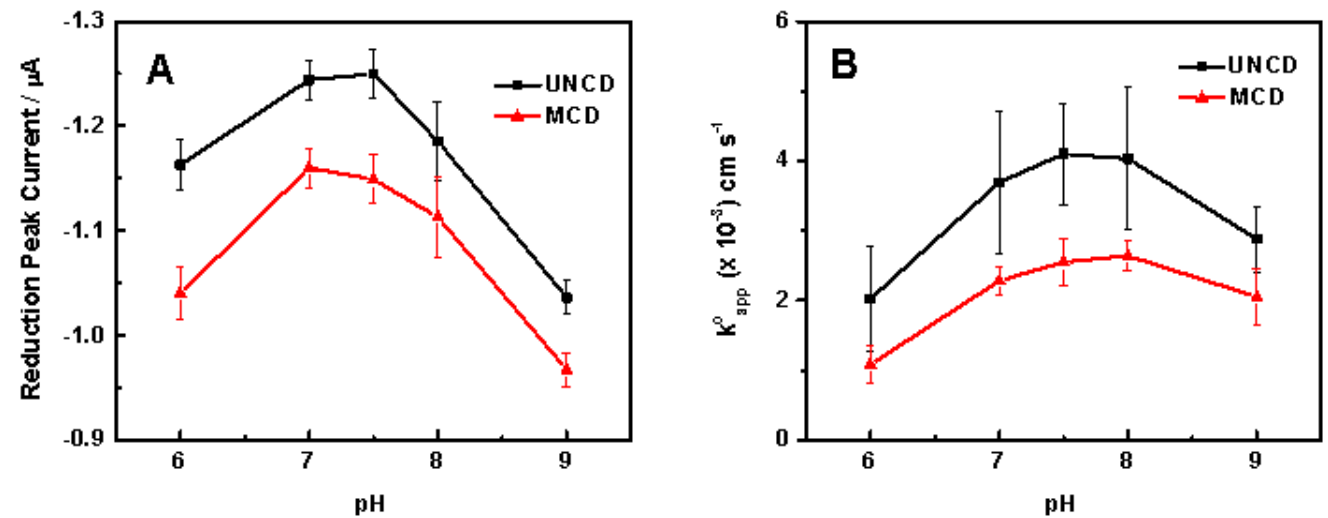

Figure 8. Plots of $(A)$ the reduction peak current, $i_{p c}$, and $(B)$ the heterogeneous electrontransfer rate constant, $\mathrm{k}_{\text {app }}^{\circ}$, for cytochrome $c$ as a function of the solution $\mathrm{pH}$ for oxygenterminated B-UNCD (black) and B-MCD (red) electrodes. Cyclic voltammograms were recorded for $0.1 \mathrm{mmol} \mathrm{dm}{ }^{-3}$ cytochrome $c$ in $0.1 \mathrm{~mol} \mathrm{dm}^{-3}$ phosphate buffer of different $\mathrm{pH}$. The $\mathrm{i}_{\mathrm{pc}}$-solution $\mathrm{pH}$ data are for $20 \mathrm{mV} \mathrm{s}^{-1}$. Average and standard deviation values are shown for $n \geq 3$.

The effect of solution $\mathrm{pH}$ on the cytochrome $c$ cyclic voltammetric response was investigated between $\mathrm{pH} 6$ and 9. The isoelectric point of the protein is $\sim 10$ [57], so at these $\mathrm{pH}$ values the protein is positively charged. The buffering capacity for phosphate buffers is generally from about 5.5 to 8 so the buffering capacity of the $\mathrm{pH} 9$ solution is somewhat questionable. Nevertheless, Figure $8 \mathrm{~A}$ and $\mathrm{B}$ show plots of the reduction peak current, $\mathrm{i}_{\mathrm{pc}}$, and the heterogeneous electron-transfer rate constant, respectively, for the redox protein as a function of the solution $\mathrm{pH}$. Data are shown for oxygen-terminated B-UNCD and B-MCD electrodes. The maximum reduction current for both electrodes is observed between $\mathrm{pH} 6.5$ and 7.5. Overall, there is not a significant $\mathrm{pH}$ effect on the current magnitude. The same is true of the $\mathrm{k}_{\text {app }}^{0}-\mathrm{pH}$ data. There is a relatively minor effect of $\mathrm{pH}$ on the rate constant and the values for the B-UNCD electrodes are slightly larger than the values for the B-MCD electrodes. Table 2 presents a summary of some cyclic voltammetric data $\left(E_{1 / 2}\right.$ and $\left.\Delta E_{p}\right)$ for an 
oxygen-terminated B-UNCD and B-MCD electrode at different solution $\mathrm{pH}$. In the absence of statistical analysis, the trend in the data for both electrodes is that the midpoint potential, $E_{1 / 2}$, and the peak potential separation, $\Delta \mathrm{E}_{\mathrm{p}}$, are similar for both electrodes and relatively independent of the solution $\mathrm{pH}$.

\section{Discussion}

The diamond electrode surface chemistry, but not the surface morphology, influences the electron-transfer kinetics of cytochrome $c$. A key finding from this work is that the hydrogen-terminated diamond surface is inactive for electron transfer with this redox protein, even though this surface shows highest kinetic activity for several other inorganic redox systems [20-26,28]. Rather, the oxygenterminated diamond electrodes are the most kinetically active toward cytochrome $c$ redox chemistry. This observation is in agreement with the other reports in the literature for this redox protein on diamond electrodes [30-37]. For example, work by the Nebel group has shown the importance of chemical interactions of the protein with the diamond surface that are promoted by an oxygen-terminated surface [32-35]. These chemical forces include hydrogen bonding and dipoledipole interactions that are critical for orienting the heme edge appropriately for rapid electron exchange with the electrode. Nominal heterogeneous electrontransfer rate constants of $2-4 \times 10^{-3} \mathrm{~cm} / \mathrm{s}$ (see Fig. 8B) are seen for both oxygenterminated B-UNCD and B-MCD electrodes and are comparable to other values reported in the literature $[29,55,56]$. 

cytochrome $c$ (both dissolved in solution and adsorbed), specifically the distance dependence of the electron-transfer rate constant [58] and the impact of specific surface chemical sites on electron-transfer [59-63]. SAMs composed of carboxylic acid-terminated thiols, which provide a negatively charged surface at physiological $\mathrm{pH}$, have been used to study the electron-transfer properties of electrostatically complexed cytochrome $c$; a condition that mimics its natural binding with cytochrome $c$ oxidase $[63,64]$. This interaction involves several lysine residues on the front surface of the protein that form a ring-like pattern around the exposed heme edge and matches the arrangement of negative charges on the binding domains of the partner proteins [39]. As indicated by Yue et al. [63], molecular dynamics calculation shows that van der Waal interactions and protein-solvation energy help to stabilize the cytochrome c-enzyme complex, whereas electrostatic forces play a guiding role in the initial stage of complex formation [65]. Overall, the most important aspects for controlling the heterogeneous electron-transfer rate constant for cytochrome $c$ are the geometry or organization of the protein and how close the heme edge can approach the electrode surface [63]. The distance of closest approach and the protein structure can be controlled through manipulation of the electrode surface chemistry. Bowden et al. recognized early on the importance of electrode hydrophilicity/oxophilicity [56]. Recently, Baio et al. [66] probed the orientation of electrostatically immobilized cytochrome c. Using a COOH-SAM (negatively 
charged at neutral $\mathrm{pH}$ ) on $\mathrm{Au}$, the authors observed the protein with the heme group pointed toward the electrode. When a $\mathrm{NH}_{2}$-SAM (positively charged) was used, the protein adopted the opposite orientation with the heme group pointing away from the electrode. This example shows that changing the surface charge can have a significant impact on how close the heme center can approach the electrode (i.e., reduced electron tunneling distance). Our results further confirm that for boron-doped diamond electrodes, like other electrodes, the surface hydrophilicity/oxophilicity, and presumably surface charge, are critical for achieving rapid rates of electron transfer with purified protein.

An important question is, how do we rationalize these findings with our original report of quasi-reversible, diffusion-controlled redox chemistry for cytochrome $c$ on an as-deposited, low-oxygen, hydrophobic boron-doped ultrananocrystalline diamond electrode [29]? In that work, we reported a heterogeneous electron-transfer rate constant of $\sim 1 \times 10^{-3} \mathrm{~cm} / \mathrm{s}$ on electrodes that were presumed to be hydrogen-terminated (low in surface oxygen) because of the post-deposition hydrogen plasma treatment that was employed [29]. This post-growth treatment consisted of a 30-min hydrogen plasma treatment at the growth temperature and pressure. At the end of this treatment, the plasma was extinguished and the samples were allowed to cool from near that of the diamond growth (ca. $700-800{ }^{\circ} \mathrm{C}$ ) down to room temperature under a flow of $\mathrm{H}_{2}$ in the vacuum. 
In light of the results presented herein, we now believe that post-growth hydrogen plasma treatment in our previous work did not produce a hydrogenterminated surface as was supposed. Rather, surface oxygen was likely introduced upon exposure of the films to the air as a consequence of the cooldown procedure that was followed. A key point in the prior work is that the hydrogen plasma was extinguished with the substrates at or near the growth temperature of $700-800{ }^{\circ} \mathrm{C}$. In the absence of atomic hydrogen, which occurs once the plasma is extinguished, surface hydrogen will desorb at the high temperatures creating free radical carbon sites that can (i) couple to produce $\pi$ bonded carbon dimers on the surface and or (ii) react with $\mathrm{O}_{2} / \mathrm{H}_{2} \mathrm{O}$ upon exposure to air to form surface carbon-oxygen functionalities [67-69]. Therefore, the procedure that was followed in the prior work likely produced more of an oxygen rather than a hydrogen surface termination. We have since learned that to obtain a hydrogen-terminated surface, atomic hydrogen must be present as the substrates are being cooled down. This is accomplished, as was the case for the electrodes used in the present work, by gradually reducing the power and pressure of the post-growth hydrogen plasma until the substrate temperature reaches of ca. $400{ }^{\circ} \mathrm{C}$ or lower [67-69]. Below this temperature, the surface hydrogen is sufficiently stable and oxygenation is avoided.

Cyclic voltammetric measurements were made on the oxygen-terminated diamond thin-film electrodes to determine the diffusion coefficient for the protein, to observe how the peak current changed with the solution concentration and to 
probe for protein denaturation and electrode fouling. The diffusion coefficients determined from the slope of the $\mathrm{i}_{\mathrm{pc}}-v^{1 / 2}$ curves $\left(2.63 \times 10^{-6} \mathrm{~cm}^{2} / \mathrm{s}\right.$ for B-UNCD and $2.09 \times 10^{-6} \mathrm{~cm}^{2} / \mathrm{s}$ for B-MCD) are close to other reported values, $0.87 \times 10^{-6}$ $\mathrm{cm}^{2} / \mathrm{s}$ [1] and $1.1 \times 10^{-6} \mathrm{~cm}^{2} / \mathrm{s}[70,71]$. There was some enhancement of the oxygen reduction current in naturally-aerated electrolyte solution after potential cycling in the presence of the redox protein. This appears to be due to a small amount of adsorbed residual protein. Evidence for the adsorbed protein was the increased $\mathrm{N}$ 1s signal in the XPS data. The reason there was no detectable signals for $\mathrm{Fe}$ or $\mathrm{S}$ is unclear but could be related to a high number of $\mathrm{N}$ atoms relative to heme $\mathrm{Fe}$ and $\mathrm{S}$ in the protein and the fact that the regions of the protein containing Fe and $\mathrm{S}$ are buried within the tertiary structure such that the probablility of a photoelectron escaping from these two atoms is low. Most interesting though is the fact the residual adsorbed protein does not adversely affect the redox kinetics for dissolved cytochrome $c$. It is therefore likely that the residual adsorbed protein is at sites distinct from those where the diffusion controlled electrolysis of the protein occurs.

The peak current, $\mathrm{i}_{\mathrm{pc}}$, was observed to increase linearly with the protein concentration in solution from 0.02 to $0.2 \mathrm{mM}$ and with the scan rate ${ }^{1 / 2}$ between 2 and $100 \mathrm{mVs}$ at both oxygen-terminated diamond electrodes. These trends are expected for a semi-infinite linear diffusion-controlled redox reaction. On both oxygen-terminated B-UNCD and B-MCD electrodes, the cyclic voltammetric curve shapes were stable with potential cycling (10-20 cycles) consistent with 
the absence of protein denautration and electrode fouling. This fouling resistance is generally only observed with chromatographically-purified protein free of oligomeric contaminants $[18,19]$. Reproducible curve shapes were observed for different oxygen-terminated B-UNCD and B-MCD electrodes. While the reduction peak current, $\mathrm{i}_{\mathrm{pc}}$, and the heterogeneous electron-transfer rate constant, $\mathrm{k}_{\mathrm{app}}^{\mathrm{a}}$, exhibit maxima in the $6.5-7.5 \mathrm{pH}$ range for both electrodes, there is a relatively minor $\mathrm{pH}$ effect over the range investigated (Fig. 8). The same holds true for the midpoint potential, $\mathrm{E}_{1 / 2}$, and peak potential separation, $\Delta \mathrm{E}_{\mathrm{p}}$, as both values are generally independent of the solution $\mathrm{pH}$ (Table 2). These are the first such $\Delta \mathrm{E}_{\mathrm{p}^{-}}$ $\mathrm{pH}$ data (6-9) reported for this redox protein at diamond electrodes. In recent work with screen-printed graphite electrodes, researchers have shown that direct electron transfer in aqueous solutions is possible due to the electrostatic attraction between the positively-charged lysine goups on the heme protein and the negatively-charged carboxylate functional groups on the electrode surface $[72,73]$. The authors attributed the observed $\mathrm{pH}$ dependence of the electrontransfer kinetics to changes in the protein orientation and distance of closest approach at the electrode surface. Using three different horse heart cytochrome c mutants, researchers found good correlation between the measured rate constant and the separation distance for protein immobilized on Au [74]. Clearly, at these $\mathrm{pH}$ values, the protein has significant positive charge $[57,75]$. Research has also shown that the secondary protein structure, examined by circular dichroism, is not significantly changed over this $\mathrm{pH}$ range [75]. Therefore, we conclude that the absence of a significant $\mathrm{pH}$ effect for electron transfer at the 
oxygen-terminated B-UNCD and B-MCD electrodes is due to the fact that the oxygenated surfaces contain few anionic carboxylate groups.

To confirm this, one would need to identify the types of carbon-oxygen functional groups formed on the B-UNCD and B-MCD surfaces after the acid washing and hydrogen peroxide treatments. In principle, thus could be determined from deconvolution of the XPS C1s signal, however, this was not undertaken in the present work. Other researchers, however, have reported XPS results for oxygenated diamond films. For example, Fujishima and coworkers reported that carbonyl $(\mathrm{C}=\mathrm{O})$ and ether $(\mathrm{C}-\mathrm{O}-\mathrm{C})$ groups form on diamond $(100)$ surfaces [43] and hydroxyl (C-OH) groups form on diamond (111) surfaces after oxidation [44]. It is, therefore, likely that our oxygen-terminated B-UNCD and BMCD electrodes contained $\mathrm{C}-\mathrm{OH}$ and $\mathrm{C}-\mathrm{O}-\mathrm{C}$ functional groups with lower levels of $\mathrm{COOH}$ groups due to the absence of a significant effect of $\mathrm{pH}$ on the cyclic voltammetrically determined reduction peak current, $\mathrm{k}_{\text {app }}^{0}, \mathrm{E}_{1 / 2}$ and $\Delta \mathrm{E}_{\mathrm{p}}$. Xue et al. [76] reported how the UV/ozone treatment of carbon nanofiber electrodes improved the direct electron transfer of cytochrome $\mathrm{c}$ as compared to the untreated surface. The pretreatment increased the hydrophilicity of the surface, as measured by water contact angle, and the surface carbon-oxygen functional group content. Increases in the $\mathrm{C}-\mathrm{OH}, \mathrm{C}=\mathrm{O}$ and $\mathrm{COOH}$ functionalities were observed by XPS based on deconvolution of the C1s peak. The authors suggested that the changes in surface chemistry serve to orient the redox protein in such as way as to shorten the distance for electron transfer. The same is likely 
the case for the oxidized diamond electrodes used in this work. The surface carbon-oxygen functional groups likely interact with the exposed heme edge of the redox protein to orient the protein close to the surface through a combination of dipole-dipole, ion-dipole and hydrogen bonding interactions with uncharged surface carbon-oxygen functional groups. The orientation of cytochrome $c$ on the surface and the distance of the heme edge are probably the most important factors controlling the heterogeneous electron transfer rate. The hydrogenterminated diamond electrodes, on the other hand, do not interact strongly with cytochrome $c$ as the polarity of the surface is much lower. The weak interaction likely positions the Fe-heme in an orientation farther away from the electrode surface, thus decreasing the probability for electron transfer. The sluggish ET rate on the hydrogen-terminated surface is not due to any electrode electronic effect a fast ET kinetics are typically observed for many redox systems on this surface.

Finally, it should be noted that solid-state electron transport studies using mutant forms of cytochrome c integrated into a molecular electronic device (contacted to two electrodes) have produced useful insights on the importance of the protein's electronic coupling to the electrode surface and orientation on the current that flows through the device $[75,77,78]$. Fundamentally, the current flow through the solid-state device is an electron flux across the protein without the need for a redox process, while the current measured in the electrochemical process is due to electronsshuttling to and from the $\mathrm{Fe}(\mathrm{III})$ and $\mathrm{Fe}(\mathrm{II})$ oxidation 
states of the heme. Removing the Fe redox center from the porphyrin completely eliminates the redox peaks but has little effect on the current flow in the solidstate measurement [77]. In contrast removing the porphyrin ring irreversibly alters the protein conformation and reduces current flow in the solid-state measurement. Importantly, the solid-state measurements revealed a general trend of greater current flow when the heme is closest to the electrode (covalently or electrostatically bound) $[77,78]$. The results, which have relevance for solution-based electron transfer with the redox protein, suggest that the Fe heme cofactor-electrode proximity and likely the cofactor-electrode coupling are important for the most efficient current flow. Evidence for this was the fact that the mutant with its cofactor closest to the electrode had the lowest temperature dependent current flow.

\section{Conclusions}

The electroactivity of dissolved horse heart cytochrome $c$ was investigated at hydrogen and oxygen-terminated microcrystalline and ultrananocrystalline boron-doped diamond thin films. The role of the surface chemistry and film morphology were investigated. The following are key findings from the work.

1. The film morphology had little effect on the heterogeneous electron-transfer rate constant for cytochrome $c$. In contrast, the surface chemistry was much more influential. The highest redox activity was found on the oxygen-terminated electrodes. In contrast, littl activity was observed on the hydrogen-terminated 
diamond electrodes. $\mathrm{k}^{\circ}$ app values were similar for oxygen-terminated microcrystalline and ultrananocrystalline diamond thin films.

2. Heterogeneous electron-transfer rate constants in the $2-4 \times 10^{-3} \mathrm{~cm} \mathrm{~s}^{-1}$ range were observed on both diamond film types when oxygen terminated.

3. Diffusion-controlled voltammetric behavior was observed on both diamond film types when oxygen terminated. The diffusion coefficient was calculated to be $\sim 2$ x $10^{-6} \mathrm{~cm}^{2} / \mathrm{s}$. Stable cyclic voltammetric curves were observed with multiple cycles on both electrodes when oxygen terminated indicating the absence of any electrode fouling by denatured protein.

4. The cyclic voltammetric peak current increased with the solution concentration of cytochrome $c$ at concentrations from 0.02 to $0.2 \mathrm{mM}$. There was a minor effect of solution $\mathrm{pH}$ on the cyclic voltammetrically-determined reduction peak current, $\mathrm{E}_{1 / 2}, \Delta \mathrm{E}_{\mathrm{p}}$ and $\mathrm{k}_{\text {app }}^{\mathrm{a}}$ at either oxygen-terminated diamond electrode.

5. The polar carbon-oxygen functional groups likely orient the redox protein with the Fe heme edge close to the electrode surface through dipole-dipole, ion-dipole and hydrogen bonding interactions. This leads to relatively rapid rates of electron transfer. In contrast, the low polarity, hydrogenated surface may interact with the protein in such a way as to position the the Fe heme farther from the electrode. The greater distance between the redox center and the electrode reduces the electron tunneling probability and results in a significantly reduced rate of electron transfer. 


\section{Acknowledgement}

This research was sponsored by grants from the National Science Foundation (CHE-0616730, GMS) and the NIH (GM096132, DAP). Aspects of the work were also supported by the Army Research Office through grant W911NF-12-R-0011. The authors thank Dr. Per A. Askeland from at Michigan State University for his help with the XPS measurements and Dr. Denise A. Mills, also from Michigan State University, for her help with the protein purification. 


\section{References}

1. Moore, G. R.; Williams, R. J. P. Eur. J. Biochem. 1980, 103, 523-532.

2. Moore , G. R.; Huang, Z-X.; Eley, C. G. S.; Barker, H. A.; Williams, G.; Robinson, M. N.; Williams, O. J. P. Faraday Discuss. Chem. Soc. 1982, 74, 311-329. Stellwagen, E. Nature 1978, 275, 73-74.

3. Kuwana, T.; Heineman W. R. Bioelectrochem. Bioenergetics 1974, 1, 389406.

4. Haas, A. S.; Pilloud, D. L.; Reddy, K. S.; Babcock, G. T.; Moser C. C.; Blaise J. K.; Dutton, P. L. J. Phys. Chem. B 2001, 105, 11351-11362.

5. Murgida, D. H.; Hilderbrandt, P. Acc. Chem. Res. 2004, 37, 854-861.

6. Hawkridge F. M.; Taniguchi, I. Electrochemistry of Heme Proteins in The Porphyrin Handbook. Kadish, K. M.; Smith, K. M.; Guilard R. eds. Academic Press, 2000, pp. 191-202.

7. Burgess, J. D.; Hawkridge, F.M. Direct Electrochemistry of Proteins and Enzymes at Electrodes in Electrochemical Methods for Biological Molecules. Brajter-Toth, A.; Chambers J. Q. eds. Marcel Dekker (New York) 2002, pp. 109-142.

8. Gui, Y.; Kuwana, T. J. Electroanal. Chem. 1987, 226, 199-209.

9. Eddowes, M. J.; Hill, H. A. O. J. Chem. Soc. Chem. Commun. 1977, 771 772.

10. Armstrong, F. A.; Hill, H. A. O.; Walton, N. J. Acc. Chem. Res. 1988, 21, 407-413.

11. Rush, J. D.; Lan, J.; Koppenol, W. H. J. Am. Chem. Soc. 1987, 109, 26792682.

12. Daido, T.; Akaike, T. J. Electroanal. Chem. 1993, 344, 91-106.

13. Lojou, E.; Bianco, P. J. Electroanal. Chem. 2000, 485, 71-80.

14. Liu, H.-H.; Lu, J.-L.; Zhang, M.; Pang, D.-W.; Abruña, H. D. J. Electroanal. Chem. 2003, 544, 93-100.

15. Runge, A. F.; Saavedra, S. S. Langmuir 2003, 19, 9418-9424.

16. Zhou, J.; Lu, X.; Hu, J.; Li, J. Chem. Eur. J. 2007, 13, 2847-2853. 
17. Armstrong, F. A.; Cox, P. A.; Hill, H. A. O.; Lowe, V. J.; Oliver, B. N. J. Electroanal. Chem. 1987, 217, 331-366.

18. Bowden, E. F.; Hawkridge, F. M.; Chlebowski, J. F.; Bancroft, E. E.; Thorpe, C.; Blount, H. N. J. Am. Chem. Soc. 1982, 104, 7641-7644.

19. Hawkridge, F. M.; Taniguchi, I. Comments Inorg. Chem. 1995, 17, 163187.

20. Granger, M. C.; Witek, M.; Xu, J.; Hupert, M.; Hanks, A.; Koppang, M. D.; Butler, J. E.; Lucazeau, G.; Mermoux, M.; Strojek, J. W.; Swain, G. M. Anal. Chem. 2000, 72, 3793-3804.

21. Peckova, K.; Barek, J. Curr. Org. Chem. 2011, 15, 3014-3028.

22. Fischer, A.; Show, Y.; Swain, G. M. Anal. Chem. 2004, 76, 2553-2560.

23. Wang, S.; Swope, V. M.; Butler, J. E.; Feygelson, T.; Swain, G.M. Diam. Rel. Mater. 2009, 18, 669-677.

24. Luong, J. H. T.; Male, K. B.; Glennon, J. D. Analyst 2009, 134, 18651979.

25. Swain, G. M. Electrically Conducting Diamond Thin-Films: Advanced Electrode Materials for Electrochemical Technologies in Electroanalytical Chemistry; Bard, A. J.; Rubinstein, I. eds. Marcel Dekker (New York) 2004, vol. 22; pp. 181-277.

26. Granger, M. C.; Xu, J.; Strojek, J. W.; Swain, G. M. Anal. Chim. Acta 1999, 397, 145-161.

27. Gruen, D. M. Annu. Rev. Mater. Sci. 1999, 29, 211-259.

28. Show, Y.; Witek, M. A.; Sonthalia, P.; Gruen, D. M.; Swain, G. M. Chem. Mater. 2003, 15, 879-888.

29. Haymond, S.; Babcock, G. T.; Swain, G. M. J. Am. Chem. Soc. 2002, 124, 10634-10635.

30. Marken, F.; Paddon, C. A.; Asogan, D. Electrochem. Commun. 2002, 4, 62-66.

31. Zhou, Y.; Zhi, J.; Zou, Y.; Zhang, W.; Lee, S.-T. Anal. Chem. 2008, 80, 4141-4146.

32. Hoffman, R.; Kriele, A.; Kapta, S.; Smirnov, W.; Yang, N.; Nebel, C. E. Phys. Status Solidi A 2010, 207, 2073-2077. 
33. Yang, N.; Hoffman, R.; Smirnov, W.; Kriele, A.; Nebel, C. E. Electrochem. Comm. 2010, 12, 1218-1221.

34. Yang, N.; Hoffman, R.; Smirnov, W. Nebel, C. E. Diam. Rel. Mater. 2011, 20, 269-273.

35. Hoffman, R.; Kriele, A.; Obloh, H.; Takuda, N.; Smirnov, W.; Yang, N.; Nebel, C.E. Biomater. 2011, 32, 7325-7332.

36. Gopolan, A. I.; Lee, K-P.; Komathi, S. Biosensors Bioelectronics 2010, 26, 1638-1643.

37. Caterino, R.; Csiki, R.; Wiesinger, M.; Sachsenhauser, M.; Stutzmann, M.; Garrido, J. A.; Cattani-Scholz, A.; Speranza, G.; Janssens, S. D.; Haenan, K. ACS Appl. Mater. Interface. 2014, 6, 13909-13916.

38. Dai, Y.; Zheng Y.; Swain, G. M.; Proshlyakov, D. A. Anal. Chem. 2011, 83, 542-548.

39. Rivas, L.; Murgida, D. H.; Hildebrandt, P. J. Phys. Chem. B 2002, 106 , 4823-4830.

40. Mori, Y.; Kawarada, H.; Hiraki, A. Appl. Phys. Lett. 1991, 58, 940-941.

41. Yagi, I.; Notsu, H.; Kondo, T.; Tryk, D. A.; Fujishima, A. J. Electroanal. Chem. 1999, 473, 173-178.

42. Pehrsson, P. E.; Mercer, T. W. Surf. Sci. 2000, 460, 49-66.

43. Notsu, H.; Yagi, I.; Tatsuma, T.; Tryk, D. A.; Fujishima, A. J. Electroanal. Chem. 2000, 492, 31-37.

44. Notsu, H.; Fukazawa, T.; Tatsuma, T.; Tryk, D. A.; Fujishima, A. Electrochem. Solid-State Lett. 2001, 4, H1-H3.

45. Loh, K. P.; Xie, X. N.; Yang, S. W.; Zheng, J. C. J. Phys. Chem. B 2002 , $106,5230-5240$.

46. Brautigan, D. L.; Ferguson-Miller, S.; Margoliash, E. J. Biol. Chem. 1978, 253, 130-139.

47. Wu, Y.; Hu, S. Bioelectrochem. 2006, 65, 105-112.

48. Zhou, J.; Lu, X.; Hu, J.; Li, J. Chem. Eur. J. 2007, 13, 2847-2853.

49. Wang, L.; Wang, E. Electrochem. Comm. 2004, 6, 49-54.

50. Ding, X.; Yang, M.; Hu, J.; Li, Q.; McDougall, A. Microchimica Acta 2007, 158, 65-71. 
51. Steinmuller-Nethl, D.; Kloss, F. R.; Najam-Ul-Haq, M.; Rainer, M.; Larsson, K.; Linsmeier, C.; Kohler, G.; Fehrer, C.; Lepperdinger, G.; Liu, X.; Memmel, N.; Bertel, E.; Huck, C. W.; Gassner, R.; Bonn, G. Biomaterials 2006, 27, 4547-4556.

52. Su, Y. O.; Kuwana, T.; Chen, S-M. J. Electroanal. Chem. 1990, 288, 177195.

53. Okunola, A.; Kowalewska, B.; Bron, M.; Kulesza, P. J.; Schuhmann, W. Electrochim. Acta 2009, 54, 1954-1960.

54. Nicholson, R. S. Anal. Chem. 1965, 37, 1351-1355.

55. Dong, S.; Chi, Q. Bioelectrochem. Bioenergetics 1992, 29, 237-245.

56. Bowden, E. F.; Hawkridge, F. M.; Blount, H. N. J. Electroanal. Chem. 1984, 161, 355-376.

57. Lvov, Y.; Ariga, K.; Ichinose, I.; Kunitake, T. J. Am. Chem. Soc. 1995, 117, 6117-6123.

58. Wei, J.; Liu, H.; Dick, A. R.; Yamamoto, H.; He, Y.; Waldeck, D. H. J. Am. Chem. Soc. 2002, 124, 9591-9599.

59. Avila, A.; Gregory, B. W.; Niki, K.; Cotton, T. M. J. Phys. Chem. B 2000, 104, 2759-2766.

60. Wei, J. J.; Liu, H. Y.; Niki, K.; Margolish, E.; Waldeck, D. H. J. Phys. Chem. B 2004, 108, 16912-16917.

61. Leopold, M. C.; Bowden, E. F. Langmuir 2002, 18, 2239-2245.

62. Murgida, D. H.; Hildebrandt, P. J. Phys. Chem. B 2001, 105, 1578-1586.

63. Yue, H.; Waldeck, D. H.; Petrovic, J.; Clark, R. A. J. Phys. Chem. B 2006, $110,5062-5072$.

64. Collinson, M.; Bowden, E. F.; Tarlov, M. J. Langmuir 1992, 8, 1247-1250.

65. Cunha, C. A.; Romao, M. J.; Sadeghi, S. J.; Valetti, F.; Gilardi, G.; Soares, C. M. J. Biol. Inorg. Chem. 1999, 4, 360-374.

66. Baio, J. E.; Weidner, T.; Ramney, D.; Pruzinsky, L.; Castner, D. G. Biointerphases 2013, 8, 18-26.

67. Landstrass, M. I.; Ravi, K. V. Appl. Phys. Lett. 1989, 55, 1391-1393.

68. Looi, H. J.; Pang, L. Y. S.; Molloy, A. B.; Jones, F.; Foord, J. S.; Jackman, R. B. Diam. Rel. Mater. 1989, 7, 550-555. 
69. Maier, F.; Riedel M.; Mantel, B.; Ristein, J.; Ley, L. Phys. Rev. Lett. 2000, 85, 3472-3475.

70. Theorell, H. Biochem. Z. 1936, 285, 207-218.

71. Ehrenberg, A. Acta Chem. Scand. 1957, 11, 1257-1270.

72. Gomez-Mingot, M.; Iniesta, J.; Montiel, V.; Kadara, R. O.; Banks, C.E. Analyst 2011, 136, 2146-2150.

73. Gomez-Mingot, M.; Montiel, V.; Banks, C. E.; Iniesta, J. Analyst 2014, $139,1442-1448$.

74. Bortolotti, C.A.; Borsari, M.; Sola, M.; Chertkova, R.; Dolgikh, Kotlyar, A.; Facci, P. J. Phys. Chem. C 2007, 111, 12100-12105.

75. Amdursky, N.; Pecht, I.; Sheves, M.; Cahen, D. J. Am. Chem. Soc. 2013, $135,6300-6306$.

76. Xue, Q.; Kato, D.; Kamata, T.; Guo, Q.; You, T.; Niwa, O. Anal. Sci. 2013, 29, 611-618.

77. Amdursky, N.; Ferber, D.; Pecht, I.; Sheves, M.; Cahen, D. Phys. Chem. Chem. Phys. 2013, 15, 17142-17149.

78. Amdursky, N.; Ferber, D.; Bortolotti, C. A.; Dolgikh, D. A.; Chertkova, R. V.; Pecht, I.; Sheves, M.; Cahen, D. PNAS, 2014, 111, 5556-5561. 


\section{List of Figures}

Figure 1. X-ray photoelectron survey spectra of B-UNCD electrodes (A) asdeposited, (B) after oxygenation (oxygen terminated) and (C) after rehydrogen (hydrogen terminated).

Figure 2. X-ray photoelectron survey spectra of oxygen-terminated (A) BMCD and (B) B-UNCD electrodes after immersion and potential cycling in a solution of $0.1 \mathrm{mmol} \mathrm{dm}{ }^{-3}$ cytochrome $c$ in $0.1 \mathrm{~mol} \mathrm{dm}^{-3} \mathrm{NaCl}+0.01 \mathrm{~mol} \mathrm{dm}^{-3}$ Tris- $\mathrm{HCl}$ buffer $(\mathrm{pH} 7)$. The electrodes were rinsed with ultrapure water after the cycling.

Figure 3. Cyclic voltammetric $i-E$ curves for a hydrogen-terminated B-UNCD film showing $(A)$ the initial background response in $0.1 \mathrm{~mol} \mathrm{dm}^{-3} \mathrm{NaCl}$ and 0.01 mol dm ${ }^{-3}$ Tris-HCl buffer $(\mathrm{pH} \mathrm{7),} \mathrm{(B)} \mathrm{a} \mathrm{repeat} \mathrm{background} \mathrm{scan} \mathrm{after} \mathrm{exposure} \mathrm{to}$ a cytochrome $c$ solution and $(C)$ the response in $0.1 \mathrm{mmol} \mathrm{dm}^{-3}$ cytochrome $c$ plus $0.1 \mathrm{~mol} \mathrm{dm}^{-3} \mathrm{NaCl}$ and $0.01 \mathrm{~mol} \mathrm{dm}^{-3}$ Tris-HCl buffer $(\mathrm{pH} \mathrm{7)}$. Scan rate $=20$ $\mathrm{mV} \mathrm{s}$. Electrode area $=0.2 \mathrm{~cm}^{2}$. The scan was initiated at $0.3 \mathrm{~V}$ and the potential swept initially in the negative direction.

Figure 4. Cyclic voltammetric $i-E$ curves for $0.1 \mathrm{mmol} \mathrm{dm}^{-3}$ cytochrome $c$ plus $0.1 \mathrm{~mol} \mathrm{dm}^{-3} \mathrm{NaCl}$ and $0.01 \mathrm{~mol} \mathrm{dm}^{-3}$ Tris-HCl buffer $(\mathrm{pH} 7)$ at oxygen-terminated (A) B-UNCD and (B) B-MCD electrodes. Curves are shown for different scan numbers (1-10). The scans were initiated at $0.3 \mathrm{~V}$ and the potential swept initially in the negative direction.

Figure 5. Cyclic voltammetric background $i-E$ curves for an oxygenterminated B-UNCD electrode in $0.1 \mathrm{~mol} \mathrm{dm}^{-3} \mathrm{NaCl}$ plus $0.01 \mathrm{~mol} \mathrm{dm}^{-3}$ Tris- $\mathrm{HCl}$ buffer $(\mathrm{pH} 7)$. Scan rate $=20 \mathrm{mV} \mathrm{s}^{-1}$. Electrode area $=0.2 \mathrm{~cm}^{2}$. The curves were recorded in buffer before (black, solid line) and after (red, dashed dot line and blue, dashed line) cycling in a cytochrome $c$ solution. The black and blue curves were recorded in solutions deaerated with $\mathrm{N}_{2}$ while the red curve was recorded in naturally aerated electrolyte solution. The scan was initiated at $0.3 \mathrm{~V}$ and the potential swept initially in the negative direction.

Figure 6. Cyclic voltammetric $i-E$ curves for $0.1 \mathrm{mmol} \mathrm{dm}^{-3}$ cytochrome $c$ in $0.1 \mathrm{~mol} \mathrm{dm}^{-3} \mathrm{NaCl}$ and $0.01 \mathrm{~mol} \mathrm{dm}^{-3}$ Tris- $\mathrm{HCl}(\mathrm{pH} 7)$ on an oxygen-terminated BUNCD electrode at different scan rates from $2-100 \mathrm{mV} \mathrm{s}^{-1}$. Electrode area $=0.2$ $\mathrm{cm}^{2}$. The scan was initiated at $0.3 \mathrm{~V}$ and the potential swept initially in the negative direction. The fifth cycle is shown for each scan rate.

Figure 7. (A) Plot of the reduction peak current, $\mathrm{i}_{\mathrm{pc}}$, for $0.1 \mathrm{mmol} \mathrm{\textrm {dm } ^ { - 3 }}$ cytochrome $c$ in $0.1 \mathrm{~mol} \mathrm{dm}^{-3} \mathrm{NaCl}$ and $0.01 \mathrm{~mol} \mathrm{dm}^{-3}$ Tris-HCl buffer $(\mathrm{pH} \mathrm{7)}$ as a function of the (scan rate) $)^{1 / 2}$. (B) Plot of $i_{p c}$ versus the cytochrome $c$ concentration in $0.1 \mathrm{~mol} \mathrm{dm}^{-3} \mathrm{NaCl}$ and $0.01 \mathrm{~mol} \mathrm{dm}^{-3}$ Tris- $\mathrm{HCl}$ buffer $(\mathrm{pH} 7)$. Both sets of data 
were created from cyclic voltammetric i-E curves recorded with an oxygenterminated B-UNCD electrode. The $\mathrm{i}_{\mathrm{pc}}$-concentration data are for a $20 \mathrm{mV} \mathrm{s}^{-1}$ scan rate.

Figure 8. Plots of $(A)$ the reduction peak current, $i_{p c}$, and $(B)$ the apparent heterogeneous electron-transfer rate constant, $\mathrm{k}^{\circ}{ }_{\text {app}}$, for cytochrome $c$ as a function of the solution $\mathrm{pH}$ for oxygen-terminated B-UNCD (black) and B-MCD (red) electrodes. Cyclic voltammograms were recorded for $0.1 \mathrm{mmol} \mathrm{dm}^{-3}$ cytochrome $c$ in $0.1 \mathrm{~mol} \mathrm{dm}^{-3}$ phosphate buffer of different $\mathrm{pH}$. The $\mathrm{i}_{\mathrm{pc}}$-solution $\mathrm{pH}$ data are for $20 \mathrm{mV} \mathrm{s}^{-1}$. Average and standard deviation values are shown for $n \geq 3$. 


\section{TABLES}

Table 1. Apparent heterogeneous electron-transfer rate constant, $k_{a p p}^{o}$, calculated from cyclic voltammetric data ( $\Delta \mathrm{E}_{\mathrm{p}}$ vs. scan rate trends).

\begin{tabular}{ccc}
\hline $\begin{array}{c}\text { Scan rate } \\
\text { V/s }\end{array}$ & \multicolumn{2}{c}{$k_{\text {app }}^{o}\left(\times 10^{-3} \mathrm{~cm} / \mathrm{s}\right)^{\star}$} \\
\hline 0.005 & $3.55 \pm 1.18$ & B-MCD \\
0.01 & $2.90 \pm 0.58$ & $2.26 \pm 0.31$ \\
0.02 & $3.28 \pm 0.72$ & $2.55 \pm 0.35$ \\
0.05 & $3.29 \pm 0.94$ & $2.33 \pm 0.34$ \\
0.1 & $3.46 \pm 1.23$ & $2.80 \pm 0.30$ \\
\hline Avg. & $3.48 \pm 1.25$ & $2.38 \pm 0.72$ \\
\hline
\end{tabular}

Calculations were performed with $T=298 \mathrm{~K}, \mathrm{D}_{0}=\mathrm{D}_{\mathrm{R}}=1.1 \times 10^{-6} \mathrm{~cm}^{2} / \mathrm{s}$ and $\alpha=0.5$ [54]. Oxygen-terminated B-MCD and B-UNCD thin-film electrodes were used for the measurements.

Table 2. $\quad \mathrm{pH}$ dependence of the cyclic voltammetric midpoint potential, $\mathrm{E}_{1 / 2}$, and peak potential separation, $\Delta E_{p}$, for cytochrome $c$ on an oxygen-terminated B-UNCD and B-MCD electrode.

\begin{tabular}{cccc}
\hline $\mathrm{pH}$ & $\begin{array}{c}\mathrm{E}_{1 / 2}(\mathrm{mV}) \\
\text { vs. Ag/AgCl }\end{array}$ & $\begin{array}{c}\Delta \mathrm{E}_{\mathrm{p}}(\mathrm{mV}) \\
\text { B-UNCD }\end{array}$ & $\begin{array}{c}\Delta \mathrm{E}_{\mathrm{p}}(\mathrm{mV}) \\
\text { B-MCD }\end{array}$ \\
\hline 6 & 40 & 82 & 98 \\
7 & 33 & 72 & 79 \\
7.5 & 32 & 73 & 77 \\
8 & 32 & 71 & 77 \\
9 & 30 & 77 & 82 \\
\hline
\end{tabular}

The data were determined from cyclic voltammetric recordings of $0.1 \mathrm{mmol} \mathrm{dm}{ }^{-3}$ cytochrome $c$ in $0.1 \mathrm{~mol} \mathrm{dm}^{-3}$ phosphate buffer of different $\mathrm{pH}$. Scan rate $=20$ $\mathrm{mV} / \mathrm{s}$. Electrode area $=0.2 \mathrm{~cm}^{2}$. 